\title{
Transaction
}

\section{Mechanical Properties and Higher Order Structures of the Bacterial Polyester Highly Oriented Films}

\author{
Jae-Chang Lee ${ }^{* 1}$, Yukiko Furuhashi ${ }^{* 2}$,Yutaka Kawahara ${ }^{* 3}$, and Hideki Yamane ${ }^{* 3}$ \\ ${ }^{*}$ Graduate School of Science and Technology, Kyoto Institute of Technology, \\ Matsugasaki, Sakyo-ku, Kyoto 606-8585, Japan \\ ${ }^{* 2}$ Institute of Industrial Science, University of Tokyo, Komaba, Meguro-ku, \\ Tokyo 153-8505, Japan \\ ${ }^{*}$ R\&D Center for Bio-based Materials, Kyoto Institute of Technology, \\ Matsugasaki, Sakyo-ku, Kyoto 606-8585, Japan
}

\begin{abstract}
Bacterial poly(3-hydroxybutyrate-co-3-hydroxyhexanoate)(PHBH) highly oriented films were prepared by the combination of roll and uniaxial drawing processes. Compression molded films, which is rather brittle, turned to be ductile after roll drawing up to $\mathrm{x} 2$, and the films were further uniaxially drawn to a draw ratio as high as $1000 \%$. The PHBH film with the tensile strength of $178 \mathrm{MPa}$ and the modulus of $1.4 \mathrm{GPa}$ were obtained. The roll drawn PHB film showed a slight crystalline orientation of $\alpha$-form. The orientation advanced with uniaxial draw ratio and the formation of $\beta$-form crystal was observed. Relations among the processing conditions, higher order structures and mechanical properties were investigated using wide-angle X-ray diffraction, differential scanning calorimetry, and tensile measurements.
\end{abstract}

(Received 6 February, 2006 ; Accepted 20 June, 2006)

\section{Introduction}

Poly(3-hydroxybutyrate)(PHB) is produced by a wide variety of microorganisms as intracellular carbon and energy storage material [1], and has been extensively studied as a biodegradable and biocompatible thermoplastic [2-4]. However, it is well known that the processing of PHB and its copolymers into fibers, films, and other products is very hard. These polyesters have a glass transition point below room temperature, and the crystallization rate is quite low [5]. Because of these properties, the melt cools down to the room temperature without crystallization and the spherulitic crystallization occurs after processing resulting in the brittle character. Further the defect in the spherulites formed during the secondary crystallization deteriorates the mechanical properties [6, 7].

Several groups have attempted to improve the mechanical properties of PHB solution cast films. Holmes tried to obtain uniaxially and biaxially oriented films of PHB to improve the mechanical properties [4]. However, these films were too brittle to draw either uniaxially or biaxially to high ratio. De Koning et al. have reported that the stiffness and brittleness of PHB film was avoided by annealing at elevated temperatures [8]. This procedure seems to eliminate the defect in the spherulites. Barham and Keller [9] reported that the ductility of PHB films can be significantly improved by the application of cold drawing. The elongation at break measured at room temperature increases up to $300 \%$ after $300 \%$ of elongation by rolling, while as compression molded PHB film shows the elongation at break as low as $7 \%$. One can apply similar process to obtain highly oriented PHBH films with good mechanical properties.

In this study, the roll drawing was applied to the compression molded poly (3-hydroxybutyrate-co-3hydroxyhexanoate) (PHBH) films. While brittle spherulite structure tends to break easily by extension, it is possible to make a crystal orientation to some extent, without breaking in roll drawing. Roll drawn PHBH films are ductile and can be stretched to high extension ratio without breaking. Films obtained were further annealed at an elevated temperature. The objective of this study is to investigate the changes in mechanical properties and higher order structures of $\mathrm{PHBH}$ films during these processes. 


\section{Experimental}

\subsection{Materials and film preparation}

The bacterial Poly (3-hydroxybutyrate-co-3hydroxyhexanoate $)(\mathrm{PHBH})$ with an weight-average molecular weight $(\mathrm{Mw})=400,000$ and 3hydroxyhexanoate content $=7 \mathrm{~mol} \%$ was supplied by KANEKA Co. Ltd. DSC heating curves of PHBH as received and $\mathrm{PHBH}$ film as prepared were shown in Fig.1. The $\mathrm{PHBH}$ was dried in vacuo at $70^{\circ} \mathrm{C}$ for $10 \mathrm{~h}$ before film forming.

PHBH was compression molded at $150^{\circ} \mathrm{C}$ into films about $1 \mathrm{~mm}$ thick using a vacuum mold and quenched immediately to $2^{\circ} \mathrm{C}$. The films were crystallized in an oven at $40^{\circ} \mathrm{C}$ for $12 \mathrm{~h}$.

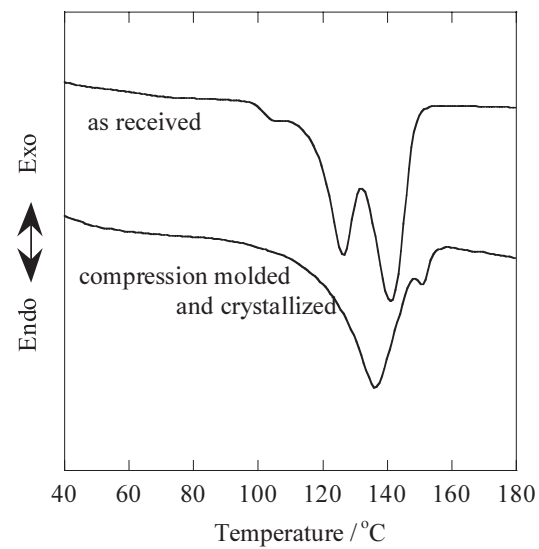

Fig. 1 DSC curves of PHBH powder as received and the film compression molded and crystallized.

\subsection{Roll and uniaxial drawing}

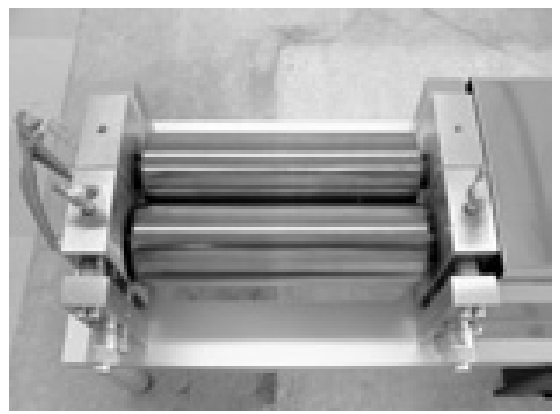

Fig. 2 Photograph of the roll drawing apparatus.

The rectangular specimens $5 \mathrm{~mm}$ x $25 \mathrm{~mm}$ were cut from crystallized PHBH film. Roll drawing was carried out by a roll drawing apparatus (Imoto Machinery Co. Ltd.) shown in Fig.2. The film can be roll drawn between two temperature controlled rolls of $40 \mathrm{~mm}$ in diameter. Rotation speed of the rolls was set at $30 \mathrm{rpm}$.

Roll drawn films were further uniaxially drawn in a hot water bath by a motor controlled uniaxial drawing apparatus. After drawing, the films were quenched in cold water.

\subsection{Annealing}

Annealing process was carried out at various temperatures and under various tensions. The drawn PHBH films were annealed in the heated air at 80, 100 and $120^{\circ} \mathrm{C}$ under the tensile stresses of 30,50 and 100 $\mathrm{MPa}$. The period for which films stayed in the heated zone was set to $5 \mathrm{~min}$.

\subsection{Thermal analysis}

Thermal property of the films was determined with a DSC (DSC3100SA, MAC Science Co. Ltd.) under $\mathrm{N}_{2}$ atmosphere. $2 \mathrm{mg}$ of specimens was sealed in an aluminum pan. A heating rate of $10^{\circ} \mathrm{C} / \mathrm{min}$ was used. Melting temperature was determined from the maximum of the endothermic peak. The crystallinity content of the specimens was determined by rating the enthalpy of melting peak to the reference melting enthalpy of the $100 \%$ crystalline homo poly(3-hydroxybutyrate), $146 \mathrm{~J} / \mathrm{g}$ reported by Barham et al [9].

\subsection{X-ray analysis}

Wide-angle X-ray diffraction (WAXD) patterns were obtained at room temperature using a nickel-filtered $\mathrm{CuK} \alpha$ radiation of wave-length $0.1542 \mathrm{~nm}$, from a Rigaku RAD2C sealed beam X-ray generator operating at $40 \mathrm{kV}$ and $18 \mathrm{~mA}$. WAXD patterns were recorded using a point-collimated beam and a flat film holder. WAXD scans were recorded on a Rigaku RINT 2100 FSL system using nickel-filtered $\mathrm{CuK} \alpha$ radiation operated at $40 \mathrm{kV}$ and $30 \mathrm{~mA}$ in a $2 \theta$ range of $6 \sim 40^{\circ}$ at a scan rate of $2^{\circ}$ min from a Rigaku RINT 2000 X-ray generator.

In order to evaluate the relative proportions of the $\alpha$ and $\beta$-crystalline forms existed in the films, the integrated intensities of $\alpha$ - and $\beta$-forms were obtained. The number of crystallites per volume was calculated using the following equation [10], derived for the structure with a uniaxial symmetry. Assuming that the X-ray intensity of a certain diffraction spot is expressed by $f(\theta, \phi)$;

\section{$J \propto \iint f(\theta, \phi) \sin ^{2} \theta \cos \theta \sin \phi d \phi d \theta$}

$$
=A \cdot \int I(2 \theta) d \theta \cdot \int I(\phi) d \phi
$$

with

$$
A=\left(\sin ^{2} \theta \cdot \cos \theta\right) / I_{P}
$$

where $I(2 \theta)$ and $I(\phi)$ represent the peak Bragg angle, peak azimuthal angle, integrated intensity in $\theta$-direction, and in $\phi$-direction. The crystallinity index $X_{c}$ between 
different crystalline forms was calculated using the following equation ;

$$
X_{c}=J /\left(r \cdot t \cdot \sum\left|F_{h k l}\right|^{2}\right)
$$

where $r, t, \sum\left|F_{h k l}\right|^{2}$ represent the X-ray intensity ratio of before and after transmittance, sample thickness, and the structure factor of corresponded miller index parameter.

Unfortunately, PHBH drawn films do not have an uniaxial symmetry and the structure factor for the b-form is not known. Accordingly, changes in the integrated intensity of the $\alpha$ - and $\beta$-forms were taken as qualitative measures of two crystalline forms.

\subsection{Mechanical properties}

Mechanical properties of the films were evaluated at room temperature by using a tensile testing machine (CATY-500BH, YONEKURA Co. Ltd.). A specimen gauge length of $20 \mathrm{~mm}$ was used. The results obtained were averaged over three samples for each condition.

\section{Results and discussion}

\subsection{Effects of the roll drawing condition on the uniaxial ductility of PHBH films}

First of all, the effect of the roll drawing condition, such as the temperature and the draw ratio on the uniaxial ductility of PHBH film, was determined. Fig.3 shows the uniaxial draw ratio achieved at $80^{\circ} \mathrm{C}$ after roll drawing up to about $\mathrm{x} 2$ at various temperatures. It is clear that the roll drawing at $40^{\circ} \mathrm{C}$ gives a great ductility to $\mathrm{PHBH}$ film. Roll drawing at higher temperatures does not improve its ductility.

To determine the effect of the roll draw ratio on the ductility, PHBH films were roll drawn up to various draw ratios at $40^{\circ} \mathrm{C}$. Fig. 4 shows the uniaxial draw ratio achieved at $80^{\circ} \mathrm{C}$ after roll drawing up to various roll draw ratios. Total draw ratios, which is the product of roll and uniaxial draw ratios, are also plotted. Roll undrawn PHBH film was brittle in nature. However, the ductility drastically improves with increasing roll draw ratio up to $\mathrm{x} 2$ and then it decreases when the high roll draw ratio was applied to PHBH film.

WAXD through view patterns of PHBH films roll drawn up to various draw ratios are shown in Figs.5 (a) (f). Ring patterns at $2 \theta=13.4$ and $16.9^{\circ}$ are identified as the reflections from (020) and (110), respectively and an arc around $2 \theta=22^{\circ}$ is the overlap of the reflections from (021), (101), and (111). These WAXD patterns indicate that the crystal orientation becomes higher with the roll draw ratio. When the roll draw ratio was low, the spherulites in the film were not deformed enough and the film did not show a high ductility. With increasing roll draw ratio, the film was more deformed and the spherulitic structure was destroyed resulting in the high ductility. At higher roll draw ratio, the molecular orientation to the roll direction was further enhanced resulting in the lower uniaxial draw ratio achieved to the same direction. Although the higher roll draw ratio decreased the achievable uniaxial draw ratio, the total draw ratio, the product of roll and uniaxial draw ratios, are still high.

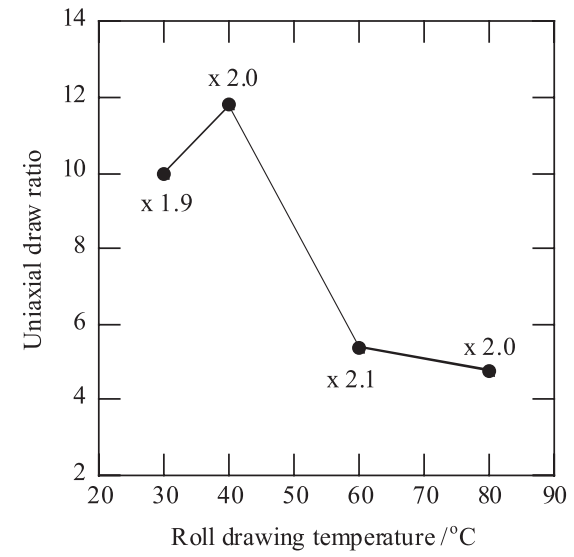

Fig. 3 Effect of the roll drawing temperature on the uniaxial draw ratio achieved. The numbers in the figure indicate the roll draw ratios.

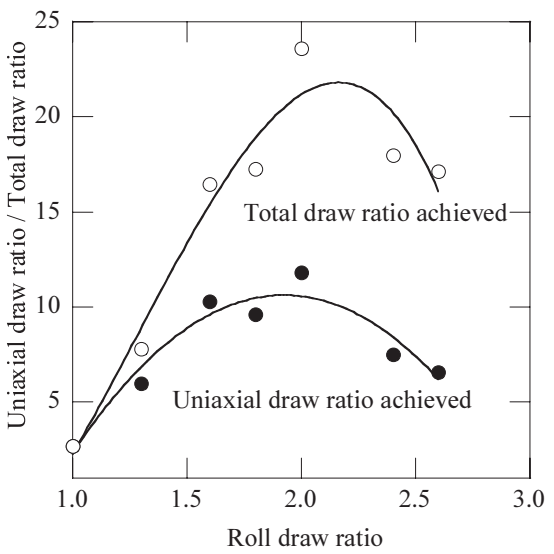

Fig. 4 Effect of the roll draw ratio at $40^{\circ} \mathrm{C}$ on the uniaxial and total draw ratio achieved.

DSC heating curve of undrawn PHBH film in Fig.1 shows a fairly broad melting peak at $140^{\circ} \mathrm{C}$ followed by a small peak at $155^{\circ} \mathrm{C}$. This large peak at a lower temperature seems to be the melting of the crystal formed during crystallization at $40^{\circ} \mathrm{C}$ after compression molding and a small peak at higher temperature may be that recrystallized during DSC measurement. Starting temperature of the melting endotherm tended to be higher 


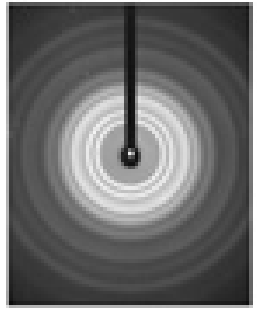

(a) undrawn

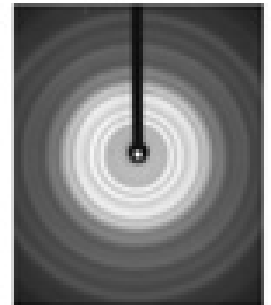

(b) $\mathrm{x} 1.3$

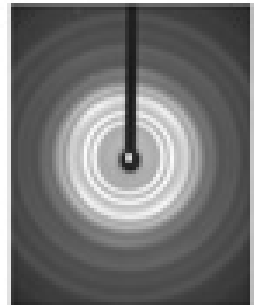

(c) $\mathrm{x} 1.6$

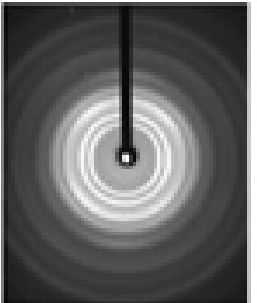

(d) $\times 1.8$

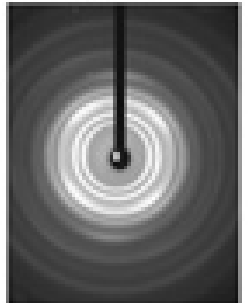

(e) $\times 2.0$

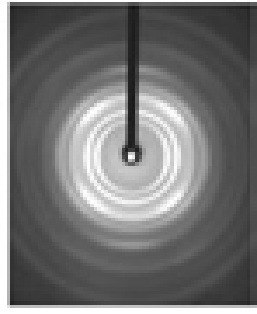

(f) $\times 2.4$

Fig. 5 WAXD pattens of PHBH films roll drawn to various draw ratios indicated at $40^{\circ} \mathrm{C}$.

and the large melting peak becomes sharper with increasing roll draw ratio as shown in Fig.6. This indicates that the spherulites turned to be oriented crystal during roll drawing. When PHBH film was roll drawn up to $\mathrm{x} 2.6$, the small peak disappear.

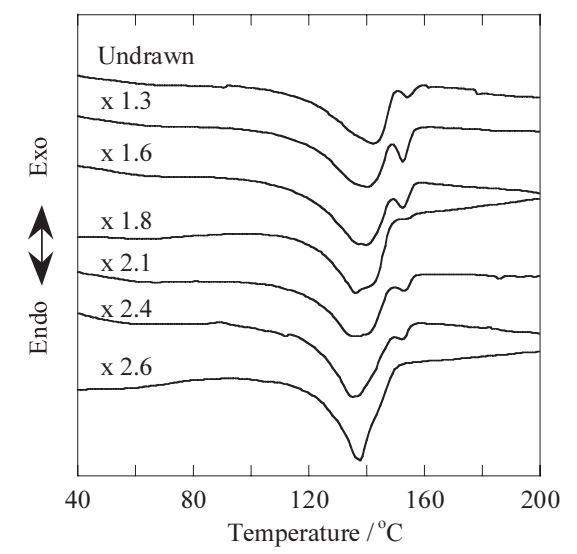

Fig. 6 DSC curves of PHBH films roll drawn at $40^{\circ} \mathrm{C}$ up to various draw ratios indicated.

From these results, the optimum temperature and the ratio for roll drawing were determined to be at $40^{\circ} \mathrm{C}$ up to x 2, and the subsequent experiments were carried out at this condition.

\subsection{Uniaxial drawing of PHBH films}

\subsubsection{Mechanical properties of the uniaxially drawn PHBH films}

Uniaxial drawing was carried out in a water bath at various temperatures ranging from $40^{\circ} \mathrm{C}$ to $98^{\circ} \mathrm{C}$. Figs. 7 (a) (c) show the mechanical properties of PHBH films uniaxially drawn at 40,60 and $80^{\circ} \mathrm{C}$.

Irrespective of the uniaxial drawing temperature, the tensile strength and modulus monotonically increase and the elongation at break decreases with a uniaxial draw ratio. High uniaxial draw ratio was achieved at 60 and 80 ${ }^{\circ} \mathrm{C}$ and the films uniaxially drawn up to $\mathrm{x} 10$ at $80^{\circ} \mathrm{C}$ showed the highest mechanical properties, the tensile strength of $178 \mathrm{MPa}$, tensile modulus of $1.4 \mathrm{GPa}$, and the elongation at break of $30 \%$. These are almost comparable to those reported for $\mathrm{PHBH}$ [11] and poly(3hydroxybutyrate-co-3-hydroxyvalerate)[12] melt spun
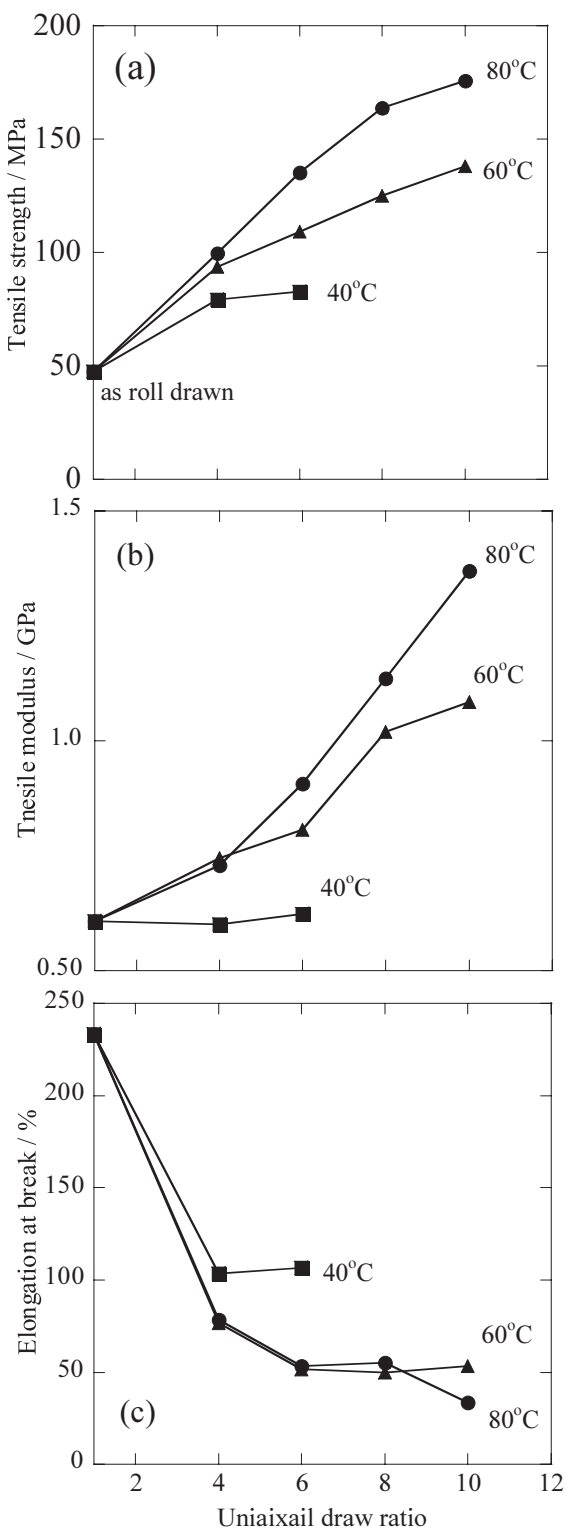

Fig. 7 Mechanical Properties of PHBH films after uniaxial drawing up to various draw ratios at various temperatures.

fibers. Although the uniaxial drawing at $40^{\circ} \mathrm{C}$ was possible, the maximum draw ratio achieved was low and the mechanical properties of resulting films are fairly low. The films were immediately broken without being stretched at $98^{\circ} \mathrm{C}$. 


\subsubsection{Higher order structure of the uniaxially drawn PHBH films}

It has been reported that the PHB generally crystallizes in a left-handed $2_{1}$ helix conformation $(\alpha$ form) $[9,13]$. The orthorhombic unit cell dimensions of $\alpha$-form was a $=0.576 \mathrm{~nm}, \mathrm{~b}=1.320 \mathrm{~nm}$, and c(fiber axis) $=0.596 \mathrm{~nm}$ [12]. In addition, another crystal form with a planar zig-zag conformation ( $\beta$-form) was observed in the highly drawn PHB fibers [10]. Orts et al. suggested that the $\beta$-form chains emanate upon stretching from the amorphous domains between $2_{1}$ helix $\alpha$-form lamellae [14]. However Furuhashi et al. demonstrated that another formation mechanism of $\beta$-form is also possible [15]. Most reports on the properties of melt spun fibers of PHB and its copolymers indicate that the tensile strength and modulus increase with the amount of $\beta$-form crystal [10, 16]. Fig. 8 shows the schematic diagram of typical WAXD pattern of the uniaxially oriented PHB fiber. Although most reflections are from $\alpha$-form, a broad spot from $\beta$ form can be observed at $2 \theta=19.7^{\circ}$ on the equator.

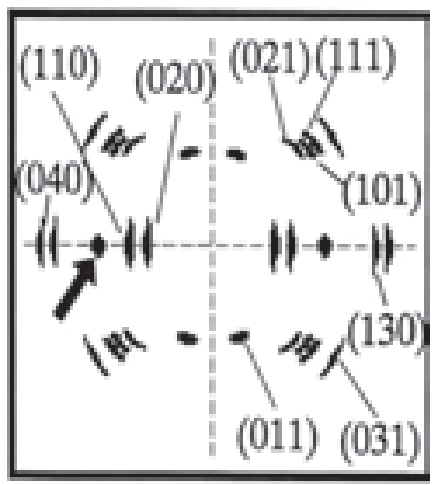

Fig. 8 Schematic explanation of typical WAXD pattern of PHB highly oriented fiber. Arrow indicates the reflection of $\beta$-form.

Figs.9 (a) (d) show the WAXD through view patterns of $\mathrm{PHBH}$ uniaxially drawn films. It should be noted that only the reflections from $\alpha$-form are observed in the WAXD pattern of the roll drawn PHBH film shown in Fig.5. However the uniaxially drawn PHBH films give highly crystalline oriented WAXD pattern and a broad spot from $\beta$-form is clearly observed on the equator. With increasing uniaxial draw ratio, the degree of the crystalline orientation advanced and the WAXD intensity of the $\beta$-form became stronger. The tendency, mechanical properties are improved with the intensity of $\beta$-form reflection in the WAXD pattern, is similar to that reported for the melt spun fibers of PHB and its copolymers [10, $16]$.

If one compare the schematic diagram of the WAXD pattern of PHB uniaxially oriented fiber shown in Fig.8 and the through view patterns of PHBH films shown in Fig.9(a) (d), one can notice some difference in these patterns. Although the reflections from (020) and (110) of the uniaxially oriented PHB fiber are arc or spot on the equator, these are rather circular in the pattern of $\mathrm{PHBH}$ film. This is very similar to the WAXD pattern of poly(3hydroxybutyrate-co-3-hydroxyvalerate) melt spun fiber reported by Furuhashi el. at [13]. Further the edge view pattern shown in Fig.9(e) is rather similar to the pattern of PHB fiber. Because of these results, it is concluded that the PHBH film does not have simple uniaxial orientation. Detailed analyses of the crystalline orientation of the PHBH films are to be described elsewhere [17].

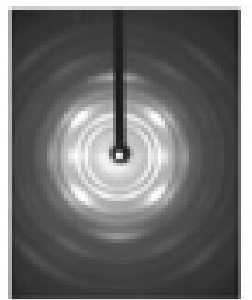

(a) $\mathrm{x} 4.0$

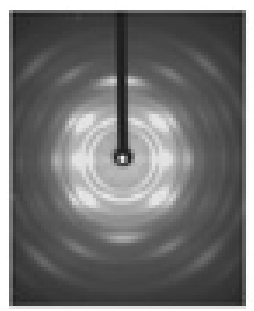

(d) $\mathrm{x} 10.0$

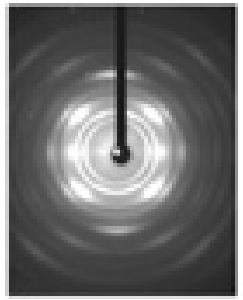

(b) $\times 6.0$

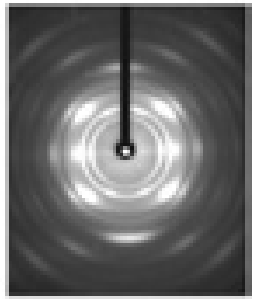

(c) $\mathrm{x} 8.0$

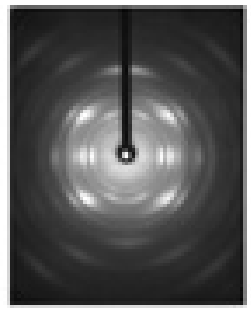

(e) $\times 10.0$ (edge)

Fig. 9 WAXD patterns of uniaxially drawn PHBH films. (a) (d) are through view patterns and (e) is an edge pattern. Numbers in the figures are the uniaxial draw ratios.

\subsection{Annealing of uniaxially drawn PHBH films}

It has been reported that the fraction of the $\beta$-form significantly increased when PHB uniaxially oriented fiber was annealed under tension [16]. In this study, the PHBH film uniaxially drawn up to $\mathrm{x} 10$ (x 20 in total draw ratio) was annealed at $100^{\circ} \mathrm{C}$ under $50 \mathrm{MPa}$ in tension for 5min. Annealing under higher tension was not possible. The film immediately broke at $120^{\circ} \mathrm{C}$.

Fig.10 shows the WAXD equatorial scans of undrawn, roll drawn and uniaxially drawn $\mathrm{PHBH}$ films. In these scans, the reflections from (020) and (110) are clearly detected. In the scan of undrawn film, overlap of the reflections from (021), (101), and (111) can be detected on the equator, since undrawn film has a random orientation. Although the undrawn and roll drawn films 
do not show any reflection from $\beta$-form, the uniaxially drawn films show a clear peak around $19.1^{\circ}$ indicating the $\beta$-formation. This peak from $\beta$-form tended to be stronger with increasing uniaxial draw ratio and it becomes sharper after annealing.

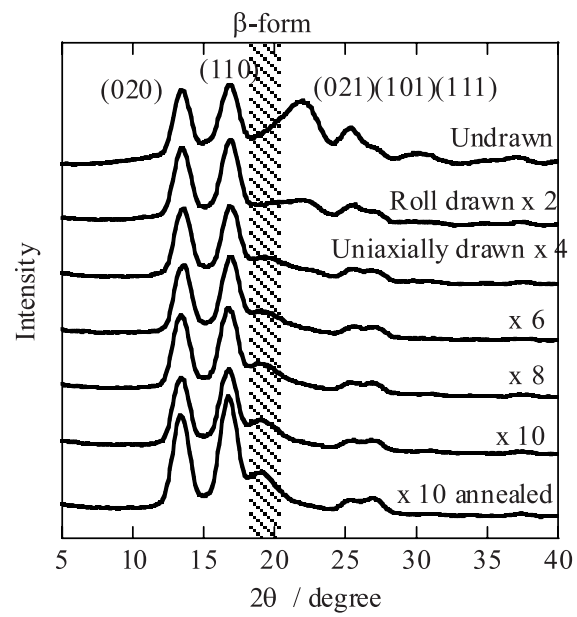

Fig. 10 WAXD equatorial scans of PHBH films.

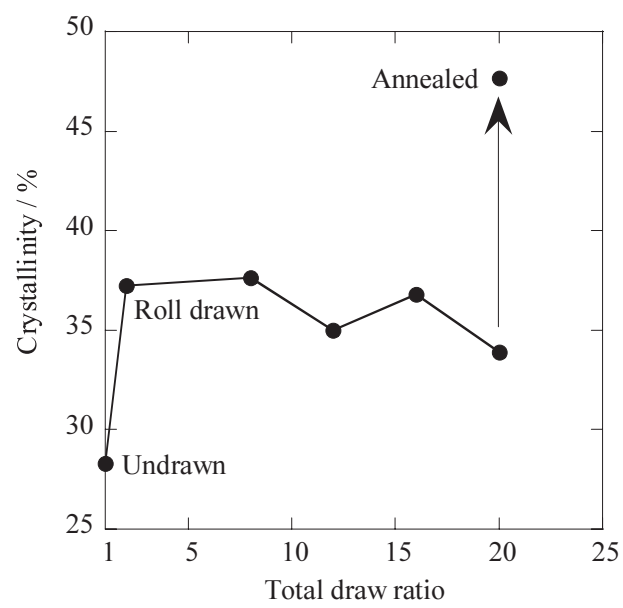

Fig. 11 Change in the crystallinity of PHBH film during various processes.

The crystallinity estimated from DSC endothermic peak shown in Fig.11 indicates that it significantly increased after roll drawing and stays almost constant irrespective of the uniaxial draw ratio. The crystallinity again significantly increased after annealing. Unfortunately, the mechanical properties did not improve as expected.

Fig.12 shows the changes in the integrated intensity of both $\alpha$ - and $\beta$-forms in the PHBH film during various processes. The integrated intensity of $\alpha$ - and $\beta$-forms was obtained from the corresponding crystalline reflection on the equator. The integration was carried out between $2 \theta$ of $13.3^{\circ}$ and $16.7^{\circ}$, and $25.3^{\circ}$, respectively, and between $60^{\circ}$ and $120^{\circ}$. It should be noted that these integrated

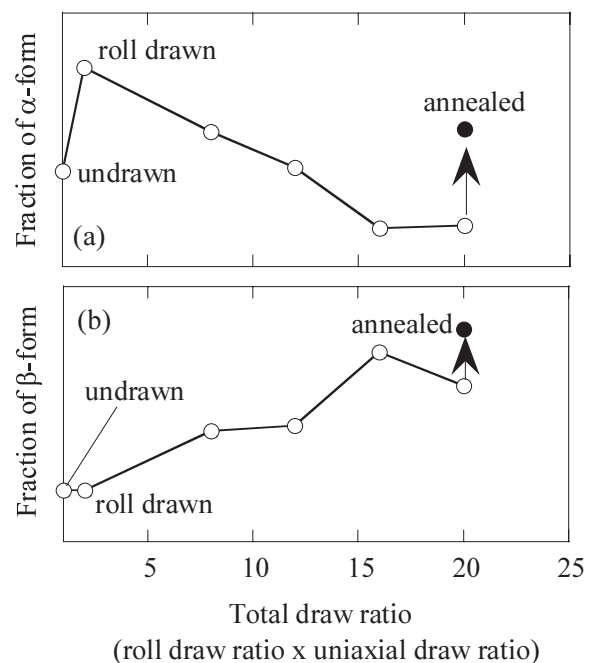

Fig. 12 Changes in the relative fraction of $\alpha$ - (a) and $\beta$-forms (b).

intensities are not the absolute crystallinities of these crystalline forms. The PHBH film before roll drawing has a $\alpha$-form crystallinity slightly less than $30 \%$ as seen in Fig.11. Roll drawing increased the $\alpha$-form crystallinity and the $\beta$-form was not detected yet. $\beta$-crystal formation started to occur when the uniaxial drawing was applied and the $\beta$-form fraction increased with increasing uniaxial draw ratio while $\alpha$-form fraction rather decreased. Annealing increased both $\alpha$ - and $\beta$-form fractions.

Although the tensile strength increased after annealing, the modulus slightly decreased and the elongation at break increased. Probably the crystalline orientation relaxed during annealing. Optimum condition for the annealing should be determined.

\section{Conclusions}

Roll drawing was applied to the poly(3hydroxybutyrate-co-3-hydroxyhexanoate ) ( $\mathrm{PHBH}$ ) compression molded films. Films after roll drawing improved the ductility and the uniaxial drawing as high as $1000 \%$ was easily achieved. As compression molded and roll drawn film consist of $\alpha$-form crystal. Both $\alpha$ - and $\beta$ form crystals coexist in the uniaxially drawn PHBH film after roll drawing and the mechanical properties of $\mathrm{PHBH}$ films improved significantly with increasing $\beta$-form fraction and the degree of crystalline orientation. WAXD patterns of the $\mathrm{PHBH}$ uniaxially drawn film revealed that the crystalline orientation in the $\mathrm{PHBH}$ film is not a simple uniaxial. Unfortunately the annealing of the PHBH films under tension did not improve the mechanical properties. Further research on the determination of the optimum annealing condition should be carried out. 


\section{References}

1. Dawes EA, Senior PJ, Adv Microbiol Physiol, 10, 135 (1973).

2. Doi Y, Microbial polyesters, New York, VCH PubLishers (1990).

3. Anderson AJ, Dawes EA, Microbiol Rev, 54, 450 (1990).

4. Holmes PA, In Bassett DC, "Developments in crystalline polymers", vol. 2, London and New York, Elsevier Applied Science (1988).

5. Ellar D, Lundgren DG, Okamura K, Marchessalt RH, J Mol Biol, 35, 489 (1968).

6. De Koning GJM, Lemstra PJ, Polymer, 34, 4089 (1993).

7. Scandola M,Ceccorulli G, Pizzoli M, Macromol Chem Rapid Commun, 10, 47 (1989).

8. De Koning GJM, Scheeren AHC, Lemstra PJ, Peeters M, Reynears H, Polymer, 35, 4598 (1994).
9. Barham PJ, Keller A, J Polym Sci Polym Phys Ed, 24, 69 (1986).

10. Furuhashi $\mathrm{Y}$, Imamura $\mathrm{Y}$, Jikihara $\mathrm{Y}$, Yamane H, Polymer, 45, 5703 (2004).

11. Tsukamoto A, Master Thesis of Kyoto Institute of Technology (2001).

12. Yamamoto T, Kimizu M, Kikutani T, Furuhashi Y, Cakmak M, Int Polym Process, 12, 29 (1997).

13. Furuhashi $\mathrm{Y}$, Ito $\mathrm{H}$, Kikutani $\mathrm{T}$, Yamamoto $\mathrm{T}$, Kimizu M, Sen'i Gakkaishi, 53, 356 (1997).

14. Orts WJ, Marchessault RH, Bluhm TL, Hamer GK, Macromolecules, 23, 5368 (1990).

15. Furuhashi $\mathrm{Y}$, Ito $\mathrm{H}$, Kikutani $\mathrm{T}$, Yamamoto $\mathrm{T}$, Kimizu M, Cakmak M, J Polym Sci, Part B Polym Phys, 36, 2471 (1998).

16. H. Yamane, K. Terao, S. Hiki, Y. Kimura. Polymer, 42, 3241 (2001).

17. Sen'i Gakkaishi, to be submitted.

18. Aoyagi Y, Doi Y, Iwata T, Polym Degrad Stab, 79, 209 (2003). 